\title{
FOOD: INVISIBLE BRIDGE CONNECTING THE PAST AND PRESENT DAY OF DIASPORIC IDENTITY
}

\author{
Sri Hariyatmi
}

School of Liberal Arts, Mae Fah Luang University, Chiang Rai- Thailand

sri.har@mfu.ac.th

\begin{abstract}
As people migrate, they move along with their emotional luggage including flavors, aromas, smells, and their gastronomical experience that also travel with them. This paper seeks to explore the role of food in the life of diaspora and how their negotiation to choose food in their new "home" has become a magical space that allows them to reconfigure their sensory system and eventually makes them a person with richer sensory systems. Several studies have been conducted to explore the relationship between personal identity and food preference. None, however, discusses how food choice influences the reconstruction of identity. Thus, this study aimed at filling the niche by exploring the relationship between food and its influence in reconstructing identity quest. This qualitative study collected its data from ten diasporas living in Thailand and Indonesia by using an informal semi-structured interview. The interview results were employed as the main data of this study. In addition, a descriptive qualitative technique was used to analyze the data. Drawing on Babha's concept of hybridity, this paper argues that firstly, food is an invisible bridge connecting the past and present-day of diasporic identity. Secondly, it also served as the shrine of negotiation for the diaspora in this study to reconfigure their identity in enduring adversity from living under a new dominant culture.
\end{abstract}

Keywords: food, memory, diaspora, negotiation, reconfigure

\section{INTRODUCTION}

\author{
"[it] is never just food- \\ it is endlessly interpretable materialized emotion" \\ Eagleton
}

Food can be as deceptively simple as something that we eat to satisfy our hunger and nourish our bodies. However, as simple as it may seem, it has layers of meanings and roles related to emotional experience. As Pazo states, "despite its core function to nourish our wellbeing, food has symbolic and connotation meanings as many as we can imagine" (Pazo, 2014, p. 11). Hence, it is worth remembering Fichsler's notion that "food not only nourishes but also signifies" (Fischler, 1978, p. 276). Furthermore, food is also an interwoven web of the past nostalgia that "strongly linked to our history and memory, therefore it "shapes our identities" (Lee, 2015, p. 5).

Thus, the link between food and identity is an intimate and complex relationship. People eat beyond merely for sustenance their physical needs, but also to establish "a direct identity between themselves and their (culture) food" (Leach 1985, via Chang, 2011, p. 1). As Barthes argues: "food is a means where people can access their past, culture, and nationality" (Barthes, 2008). To put it simply, food is a close bond that people can have in order to stay in touch with their culture.

As people migrate and have to live in a different country, their gastronomic experiences such as food choice and eating style travel with them across space and time. 
Therefore, they have to negotiate their food preferences according to a new social environment and cultural space. By doing so, they will not only modify their gastronomical experience but also at the same time integrate into a new society and in the end, reconstruct their identity. In the context of migration and diaspora, Pollock (2009) via Jagganath (2011) claims that the influence of transnational culture can be traced through foodscapes. It provides us with an opportunity to highlight the continuity of culture, innovations and the communities' choice in enhancing their identity.

It is also worth remembering that previous studies have been conducted in exploring the role of food and identity construction. Food has become an industrious issue in cultural studies in its relation to the fluidity of identity quest. Food not only has exceeded its function to nourish but also as a cultural marker of the immigrants' life and an agent that brings similar communities together (e.g. Celikel, 2010; Almerico, 2014; Lee, 2015; Perry, 2017). These studies concluded that the reflection of diasporic personal identity influences their food choice, and at the same time, food plays a significant role in their identity process. However, these existing studies have not explored how the diaspora negotiate their gastronomical experience and reconstruct their identity in their new space. This current study, therefore, attempts to present the reflective relationship between food experience and personal identity quest. It is expected that this paper will explore the role of food in the life of diaspora as well as to discover how the diaspora negotiates their food preference to survive, maintain their ties with their homeland, and at the same time construct and re-construct their identity.

\section{IDENTITY IN THE THIRD SPACE}

Hybridity is a conceptual vocabulary theorized by Bhaba, a leading figure in present-day cultural studies theory. Bhaba has developed this term from cultural and literary theory to define the construction of culture and identity within the domain of colonialism and inequality (Bhaba, 1994; 1996). As Babha points out, hybridity is a process undertaken by the colonial authority to define the Other (the colonized) identity in one universal platform. This process produces something new instead of something familiar as it is expected in the first place (Papastergiadis 1997).

Bhabha proposes that hybrid identity is positioned in a liminal or in-between space, where "strategies of selfhood that initiates new signs of identity as well as innovative sites of contestation and negotiation, in the act of defining the idea of society occurs" (Bhaba, 1994, p. 1-2). Thus, the third space that Bhabha indicates as an "interstitial passage between fixed identifications opens up for a new possibility" (Bhabha, 1994:5). This space, as Rutherford points out, enables the emergence of other positions (Rutherford, 1990, p. 211).

Hybridity, for that reason, is undoubtedly a significant concept in reading the daunting experience of the diasporic people living in a new space where they will experience "a gradual spectrum of mixed-up differences" (Geertz 1988,148). In this study, the concept of hybridity is employed to examine the role of food and how the respondents in this study negotiate their food preference and at the same time reconfigure their identity within a transnational context. 


\section{FOOD AND IDENTITY}

Food has a strong relationship with cultural identity because "human beings invest food with special meaning as metaphor" such as mooncakes for Chinese New Year and eggs for Christmas (Chang, 2011, p.36). Concerning this premise, food consumption has a profound and fundamental role that plays an important part in constructing one's identity. In other words, it is impossible to separate the relationship between food and culture. The link between food and culture is inseparable as food consumption is always connected to people's emotional memories and their attachments toward their homeland (Ju Kuo,2011, p. 11). To put it simply, food is a means to trigger profound memories of emotions, spaces, and events.

In the life of diasporas, food not only serves a crucial role but it is also a medium for them to seek comfort and connection to their root. As Mannur has synthesized: "Immigrants are geographically and temporarily far away from their childhood homes. Food has become their intellectual and emotional anchor that giving them a sense of rootedness" (Mannur, 2010, p. 11). One of the examples of comforting ways they can do is by eating their ethnic food. In Barthes' word, food is a means where people can access their past, culture, and nationality (Barthes, 2008). In the context of food and diaspora, food can be viewed as the third space as "food and foodways precipitate the emergence of hybrid identities" (Dundar 2016, p. 140).

\section{METHOD}

This study was genuinely qualitative in nature, where the data collection methods was a semi-structured informal interview using both direct (in person) and an indirect method by using social media apps. The result of the series informal qualitative interview was the primary data employed in this study.

In addition to the data collection method, this study used purposive samplings of ten respondents whose age range is between 17-35 years old. The respondents in this data are ten international students from Ethiopia, Bhutan, Cambodia, China, Indonesia, Tanzania, and Thailand. Data collection was collected between January- March 2019. This demography was selected due to the convenience and accessibility of the chosen respondents in this study. Moreover, the respondents in the present study share one core thread that they have been living abroad for at least one and a half years at the minimum and three years at the maximum. Hence, their perception of gastronomical space is high and dynamic.

\section{FINDINGS AND DISCUSSIONS}

This study intended to explore the role of food and its connection with a diasporic identity who lives under new gastronomical space. This paper argued that food served as a powerful means of an invisible bridge connecting the diasporic recollection about their past identity vis-à-vis with the culture they are experiencing in the present moment. Besides, food also serves as a shrine of negotiation where the respondents in this study reconfigure their sensory palate before and after their exposure to the new food in their new landscape.

To find the answers to the aforementioned objectives of this study, two thematic sub-chapters were comprised. The first sub-chapter presented the role of food and its 
connection to past memory and nostalgia and the next following sub-chapter mainly discussed the diasporic food's preference that has become a shrine of negotiation for them in reconstructing their identity.

\section{FOOD: HOMELAND CONNECTION}

"An immigrant travels with luggage of several kinds.

There are suitcases packed with practical goods and memorabilia and there is baggage carried only in the mind,

which contains flavors, aromas, and images from the kitchens of homeland and family.'

- Cara de Silva

When people move from their homeland to a completely different country, inevitably, they can no longer eat or have the food that they usually consume in their home culture. Living in a foreign country, the diaspora in this study eventually finds out that despite the whole new interesting horizon they encounter, they cannot help but feeling homesick when it comes to food. Following their honeymoon stage with all-new exciting things they discover in their new place, the diaspora has to handle their most urgent predicament- how to find a portion of delicious food that their sensorial memory system and their taste buds can accept. They feel nostalgic toward their homes and family; therefore, they try to consume some food with identifiable smells and familiar tastes to retrieve their homeland memory.

Lekzin, an expatriate student from the Kingdom of Bhutan mentioned that there is not a single day that he does not miss his family and friends back home. He argued that he found a remedy for his homesickness by eating similar food that his parents cook: "I usually call home and see what mum and dad cook for breakfast or dinner. Then after saw what they cooked, I go to Lamduan restaurant and imagine that I'm eating the same food. I also bring some traditional food from home to keep me connected with my people and culture". Similar thing is experienced by Sun. Whenever he misses his family, he will call his Khmer friends to cook their Khmer cuisine. "I would invite my Cambodian friends who study at the university to cook our Khmer food. It's so fortunate for me as I can find the spice that I need for Khmer food in Thailand easily. By doing so, our homesick will be lifted from our heart". Gio, an Indonesian expatriate shares similar therapy with Sun: she cooked by herself when she felt homesick and longed toward her homeland food and family. Gio explained," I usually cook when I miss home. It's not the complicated dish recipe as I could not find some of the specific spices in here, but simple food that I could prepare with the available ingredients here in Thailand." Cheng added, "Yeah...I usually cooked my dish when I missed what I had back home. I chose something simple with all the ingredients that I could find here".

Another respondent stated that by cooking her dish, she could recall all the reminiscent of sweet memories she had with her family and friends in her homeland. Food, for her, is a complex web of emotions that could bring the reminiscence of good memories and all the people she loves through the smells of the food when she cooked it. She said:" Well...people might say that I'm romanticizing things, but cooking my food is not merely an act of making dishes, it is at the same time an act of remembrance and of accessing my past, bringing back all my nostalgic memories through its smells and taste. Cooking my cultural food reminds me of who I am and the connection I have with 
my family and friends in the past while at the same time I also work to connect myself with the people and culture where I currently live". April, one of the respondents said that although she cannot cook, she still brings the instant spices of her favorite food from her country. She explained that she could use all those instant spice to 'cook' whenever she misses home. "I honestly cannot cook and don't really enjoy cooking, but living far away from home I cannot help missing my food, that's why I bring instant spices of my favorite food". On a similar note, another respondent explained that he brought with him an instant Thai chili paste so when he misses home, he can cook his food using the spice. Puphing said: "I bought some instant Thai chili paste with me before I left for Japan. I used it to cook whenever I craved for Thai spicy chicken. I can find the chicken in Japan, but the chili paste has to be chili paste from Thailand. Whenever I cook Thais spicy chicken, I feel like I get more energy from it. Its flavors and smells rejuvenate my energy, cure my longing for home make me feel more energetic to handle my tough time as a student in Japan".

Reading all the respondents' answers in this study indicates that food, for them, has become an invisible bridge that connects them to their memories and their homeland. Moreover, as they live geographically far from home, they take refuge in food as an effort to travel beyond the in-between space and hence bear the challenges of "living here and remembering another place" (Clifford, 1994, p. 255). The food they cook or other cultural stuff such as instant spices and traditional food that they bring to their new country are the artifacts that maintain the continuity of their previous identity and their new identity. Those objects help them to feel home while being away from home. As Gonzalez puts it, the moment people move from one place to another can create a feeling that they need to have certain objects to make them feel home while away from home" (Gonzales, 1995, p. 146). This act of remembrance through the food as the bridge, however, does not turn the respondents in this study into people who only seek authenticity in their food. In fact, the respondents in this study use food as a means to mediate their past and reconfigure their identity in the present. The discussion of the respondents' negotiation in choosing food and how this new food has become the negotiation site for their before and after the identity is worth discussing in the following sub-chapter.

\section{FOOD PREFERENCE: A SHRINE OF NEGOTIATION}

"[...]Our cultural, as well as personal histories, shape the ways in which we eat, so that, frequently without realizing it, we express those histories through the ways we eat, defining what can or should be eaten as well as determining what tastes we find desirable"

- Lucy M. Long

As it has been discussed in the previous sub-chapter, eating cultural food is considered as the means for the respondents in this study to connect themselves with their past (homeland). Nonetheless, they cannot always eat their ethnic food due to some reasons. For example, the scarcity of the ingredients they need, to cook their own food, or that their food is not available in their new 'home'. 
Their food choice, however, will be highly influenced by what they have in their past. To put it simply, what they eat in their childhood is eternally engraved in their mind, and to completely erase the residual memory of that taste is never possible. As Wong (2007) points out "the sensorial food experience remains in one's memory chamber, even after it is consumed vanishes or switches" (p. 121). On similar notes, Gunkel (2016) argues that food has "a magical capacity to symbolize conceptual and even philosophical framework of time, nature, or home" (p.247). Food, as described by Gabbacia, 1998, p. 6 is similar to language, (it) "makes a lasting impression that continues to shape, inform, and negotiate whom we think we are". Therefore, this subchapter will present the influence of the respondents' memory of food on the food choice that they make.

As described by Deni, tom yum (one of Thailand's famous' national dishes) is a new food in his life as a student in Thailand because tom yum reminds him of his favorite dish in Sumatra, Indonesia. He said that the taste of tom yum somehow could revive the flavor of spicy fish soup that he usually has at home. He said: "I think I love tom yum the most. The flavor is similar to the dish I had at home, the spiciness especially. Sadly, I cannot have the spicy fish soup at home, but at least tom yum's rich flavors especially the sour and spiciness can help me reviving the taste of my favorite food and help me to survive". Another respondent elaborated on how she discovered a new dish that helping her to evoke the aromas and flavor of the dish she loves: "I miss bakso (meatballs soup) the most while I live here. Nothing feels so right like having a bowl of hot meatballs and its pungent smells of garlic and pepper, along with soy sauce and sambal (chili paste) especially when I'm feeling not well. Sadly, it is too hard to find it here. Fortunately, two years ago my friend took me to a Chinese restaurant where its spicy noodle soup tastes similar to bakso. I keep coming back for another bowl since then", Laksmi explained. Lekzin also shared a similar experience as Laksmi's. He answered: "I have found Thai food that has resemblance with my food back home. The spice in that curry reminds me of the spicy food we usually eat in Bhutan. This dish helps me (well... a little bit) satisfying my longing for the spiciness of the food in my culture". Further to this comment, Magarsa, the respondent from Ethiopia explained that to find African food in Indonesia is like trying to find a needle in the haystack. He clarified that it was hard for him, in the beginning, to get used to Indonesian food. He explained: "I found it was hard to get dishes to satisfy both my hunger and my appetite. Back home I ate "injera", Ethiopia's national dish. It almost similar to nasi (rice in Indonesia), but it made of: teff", a very special grain native to Ethiopia. It is served with side dishes such as meat and vegetables. Fortunately, I found "nasi Padang". I felt so happy the first time I ate "nasi Padang" as the dish presentation looks similar to my cultural food, and the taste is acceptable to my palate. I keep coming for more of "nasi Padang" every day. It definitely has become my new favorite food".

As seen from the respondents' answers, their food preferences demonstrated how they negotiate their need to 'remember' the past, and their reflective venture to reconstruct their identity in the present. The respondent chooses dishes that have a resemblance to the food they have at their homeland as the memory of smells, aromas, and flavors cannot be completely erased from their experience. At the same time, 
however, the respondents in this study also gained new different gastronomical experience including aromas, flavors, and smells that enrich their palliative sensory system. Thus, the respondents' food choice mediates their diasporic negotiations between their past and their present.

Furthermore, their negotiation of food choice brought them to the conclusion that they have become new people who still have a trace of their prior 'home' but a new person in their new 'home'. This remark is well elaborated by Ratna who confessed that although she is still connected to her past and previous food experience, following her exposure to different food in her new landscape, she does not think that she is the same person anymore. She noted:" I realize I'm not the same person as I was. I used to be exposed to a dish with sweet as the most dominant flavor. Living in Thailand has made me a person who still appreciates the sweet flavor in my food, but with the combination of spiciness". On a similar note, Berth explained that: "I have never expected that food would be something very challenging for me. Back home, most of my food didn't taste sweet. But living in Solo, I can't help but be exposed to sweet dishes most of the time. My favorite here is "ayam geprek lada hitam" because it's salty (you know... a little bit) and a little bit spicy and yeah....sweet. Now... I still like my food, but Indonesia especially Solo has made me familiar with a sweet flavor. I think once I return to my home (Tanzania), the sweet flavor that I have in here will remain". Still, on the same note, Mano, a respondent from Thailand explained that he could not devote himself to fully enjoy his mother's cooking after living in Japan. He said:" My mom's cooking is still the best. Sadly, my exposure to Japanese food made my mom's food misses something. That's why...now my own cooking is the only thing that can satisfy my craving for Thai food and also my Japanese experience".

The respondents' discussion on their past and present food experience above proved that as diaspora, who live neither in their previous home nor completely in their new home is truly a magical experience for them. Space, where they live, is truly opening new possibilities. Their identities evolved along with their exposure to new gastronomical experience and their negotiation with it. They have become a different person from who they were as they encounter changes: "No one remains the same following cultural contact in a new place" (Sam and Berry, 2010, p. 473).

\section{CONCLUSION}

Drawing on Bhaba's notion of hybridity, this study discovered that food served as an invisible bridge for the respondents to stay connected to their homeland. In this case, the taste and smells of their homeland food play a significant role in their negotiation of reconstructing their sensory experiences. Another finding is that food is the site of negotiation for the respondents in this study to live conveniently in a dominant culture where they either have a very limited or completely have no access to their cultural food. Their negotiation has reconfigured themselves into a richer entity but at the same time, they still have trace or connection to their prior home through the taste, smells, and flavors of the native food that they still carry. Furthermore, they negotiate those pungent native flavors and aromas with the new smells and tastes of their new 'home' to survive in new foodscape and at the same time enrich their gastronomical practices. 
Food and identity formation is certainly an interesting journey to be explored. The result of this study is anticipated to provide a perspective in conducting research on identity construction, especially in relation to food and food preference. An important note for further exploration of food and identity quest is to employ respondents with a more diverse cultural background.

\section{REFERENCES}

Ang, I. (2003). Together-in-difference: Beyond Diaspora, into Hybridity. Asian Studies Review, 27(2), 141-154. https://doi.org/10.1080/10357820308713372

Barthes, Roland. (2008). Toward a Psychosociology of Contemporary Food Consumption. In Carole Counihan \& Penny Van Esterik (Eds.), (pp.22-24). New York: Routledge.

Celikel, Mehmet Ali. (2010). Food and Body as Markers of Identify in Timothy Mo's Sour Sweet. Seria Filologie, LXII (3), 228-232. Retrieved from: https://docplayer.net/155629203-Food-and-body-as-markers-of-identity-intimothy-mo-s-sour-sweet.html

Dundar, E. D. (2016) Immigrant Food and Trans-memory of Home in Diana Abu Jaber's the Language of Baklava and Elif Shafak's Honor. In Moha Ennaji (Ed.), New Horizons of Muslim Diaspora in North America and Europe (pp. 139-152). Houndmills: Palgrave Macmillan. https://doi.org/10.1057/9781137554963_9

Eagleton, T. (1998). Edible Ecritures. Consuming Passions (Ed.), Sian Griffiths and Jennifer Wallace (pp. 203-208). Manchester: Mandolin.

Fischler, C. (1988). Food, Self and Identity. Social Science Information 27(2), 275-292. https://doi.org/10.1177/053901888027002005

Gabaccia, D. (1998). We Are What We Eat: Ethnic Food and the Making of Americans. Cambridge: Harvard University Press.

Gunkel, A. H. (2016). Food and Culture. In Burns, G. A. Companion to Popular Culture. (pp. 245-264). Malden: John Wiley and Sons Ltd.

Hall, Stuart. (1994). Cultural Identity and Diaspora. Colonial Discourse and PostColonial Theory: A Reader. (Ed.), Patrick Williams and Laura Chrisman (pp.392-403). New York: Columbia University Press.

Homi K. Bhabha. (1994). The Location of Culture. London: Routledge.

Huang, Jingya. (2016) A Passage to Multiculturalism: Identity Formation Through Food and Memory in Bich Minh Nguyen's Stealing Buddha's Dinner: A Memoir. Master Degree Thesis. Soochow University. http://163.14.136.66:8080/bitstream/987654321/11716/1/104SCU00238005001.pdf

Jagganatt, Gerelene. (2017). Foodways and Culinary Capital in the Diaspora: Indian Women Expatriates in South Africa. Nordic Journal of African Studies 26(2), 
107-125. Retrieved from: http://www.njas.helsinki.fi/pdffiles/vol26num2/jagganath.pdf

Kuo, Hsin-Ju. (2011). Culinary Narratology in Everyday Life: The Foodways and Identity Formations of South Asian Women Immigrants in Jhumpa Lahiri's 'Mrs. Sen's' and The Namesake. Fiction and Drama 20 (2), 1-37. https://doi.org/10.1080/19438192.2013.862102

Leach, E. (1985). Claudi Levi Strauss. London: Fontana Press. Mannur, Anita. (2010) Culinary Fictions: Food in South Asian Diasporic Culture. Philadelphia:Temple UP.

Papastergiadis, N. (1997). Tracing Hybridity in Theory. Debating Cultural Hybridity: Multi- Cultural Identities and the Politics of Anti-Racism. London: Werbner, P. \& Modood.

Rutherford, J. (1990). The Third Space: Interview with Homi Bhabha. Identity, Community, Culture, Difference. London: Lawrence and Wishart.

Sam, David L. and John W. Berry. (2010). Acculturation: When Individuals and Groups of Different Cultural Backgrounds Meet. Perspectives on Psychological Science 5(4), 472-481. https://doi.org/10.1177/1745691610373075

Almerico, Gina M. ( 2014). Food \& Identity: Food Studies, Cultural \& Personal Identity. Journal of International Business and Cultural Studies. 8, 1-7. Retrieved http://www.aabri.com/manuscripts/141797.pdf

from:

Wong H. S. (2007). A taste of the past. Historically themed restaurants and social memory in Singapore. In Cheung, C.H. S. and Tan, C-B. (Eds.), Food and Foodways in Asia. Resource, Tradition and Cooking (pp. 115-128). Oxon: Routledge.

Yu-shin, Chang. (2011). Food and Identity: A socio-historical Perspective on The Evolution of Taiwanese Cuisine. Doctorate Thesis. School of Environment, Engineering, and Technology, Griffith University. https://pdfs.semanticscholar.org/2ff8/a3ce67ad3c9402325d88b301225fe9c299 6e.pdf 